contrary. high-AS Ss did experience higher levels of emotional arousal while observing the model. it is possible that their heightened emotionality interfered with vicarious learning processes.

The present results thus suggest that, under certain conditions, observer-model similarity may serve to impede rather than enhance observational learning. These conditions are likely to involve the evocation of negative affective responses in the observer which interfere with observational learning. either directly or indirectly, through self-generated avoidance responses made by the observer.
REELRE ACHS

BLRNSTEIN, F.. STOTLAND, F \& ZANDIR $A$. Similarity $t o$ a model and self-ebaluation. Journal of Abnormal \& Social Puchology. 1961.62 .257 .264

BYRNE. D. Attitudes and attriction. In L. Berkowitz (1d.). Adrances in experimental social psychologs. Vol. 4. Niw Yurk: Academic Press. 1969. Pp. 35.89

RICKARD. H. C.. \& LATTAL, K. A llodel similarity and observer learning. Psychological Reports, 1967, 21.501-506.

SPENCE, K. W.. FARBER. I. E., \& MCFANN, H. H. The relation of anxiety (drive) level to performance in competitional and non-competitional paired-associates karning. Journal of Experimental Psychology. 1952 $52,306-310$.

\title{
Comparison of two types of tactile exploration in a task of mirror-image recognition
}

\author{
FRANÇOISE MARTINEZ \\ Institut de Neurophysiologie et Psychophysiologie \\ Centre National de la Recherche Scientifique, Marseille, France
}

The ability to discriminate mirror images was tested with 5-year, 6-month-, to 6-year-old children in comparing performances using either visual or tactile cues. On the tactile tasks we observed that the blindfolded Ss could perform as proficiently as sighted ones when restricted to tactile palpation of the form outlines using only the fingers together with wrist movements. However, they performed significantly worse when movement was restricted to the shoulders and the form outlines were explored with the two tips of their outstretched forefingers.

It appears to be difficult for young children to discriminate visually between identical forms presented as mirror images (Pick et al, 1966; Robinson \& Higgins, 1967), particularly when they are symmetrical about the vertical axis. The same difficulty has been observed in studies with animals. For example, Mello (1966) found similar effects with pigeons, the visual pathways of which are completely crossed. In the same way, Noble (1968) found the same difficulties with monkeys in which the optic chiasma had been sectioned.

A possible explanation of the errors observed in children involves reference to kinesthetic experience governed by a principle of symmetry about the medial sagittal plane of the body (Rudel \& Teuber, 1963;
Over \& Over, 1967). This hypothesis led us to compare tactile with visua! discriminations. In a preliminary study we compared children in a visual situation with children working in a tactile situation, using either seeing, but blindfolded, children (from 5 to 8 years of age) or blindborn children (from 5 to 14 years of age).

We asked the children in the tactile situation to recognize which of two symmetrical geometric forms presented to one hand was identical to a third perceived by the other hand. The Ss were free to explore the forms as they wanted. However, the instructions given before each trial suggested one or the other of two types of exploration: The first one mobilized the activity of the proximal segments of the arm, the second one the mobility of the fingers and the urists.

The children in the visual situation explored the three forms visually only The were asked to choose the one of two forms that was identical to a third. as in the tactile situation.

The task was mure proficiently performed in the visual situation: With this preliminary test, sighted children performed adequately at about 5 years of age. In tactile situations there were still difficulties for 7-year-old seeing but blindfolded children and some 11-year-old blind-born children.

We observed that the 7-year-old blindfolded children and the 12-year-old blind (normal IQ) did not use the first type of exploration and preferred to examine the forms with all their fingers. keeping some of them on selected reference points.

Two hypotheses could explain the results in the tactile situation: (1) The $\mathrm{S}$ s are already able to perform adequately because of their older age and choose the second type of exploration because it appears more usual: the younger children use the suggested exploration either because of imidity or lack of initiative and so will fail anyhow. (2) The type of exploration (fingers and wrists) will be chosen by the older children because it provides information fitting the transfer in the conventional (visual) context.

To test these two hypotheses we proposed an experiment in which the two types of exploration were standardized and given to all the $S$ s working in a tactile situation.

\section{APPARATUS}

Two series of 20 items were used in this experiment. Each item consisted of two velvet geometric and nonsense two-dimensional forms on $15 \times 15 \mathrm{~cm}$ square cardboard sheets. These sheets were presented on a cant board (45 deg) and were separated according to the shoulder breadth of each child.

SUBJECTS AND PROCEDURE

The $S s$ were 40 seeing prinary-school children, male and female, between 5 years, 6 months and 6 years of age.

They were divided into two conditions: tactile condition $(\mathrm{T})$ and visual condition (V).

In front of each pair of forms on the cardboard sheets, the $S$ was asked to detect as different two symmetrical forms (mirror images) or as identical two figures oriented in the same direction, that is, superimposable by a movement of translation as in the visual context of adults.

In the $T$ condition, the $S s$ were blindfolded. They had to perceive the forms with their two hands. the right hand on the right form and the left hand on the 


\section{left hand}
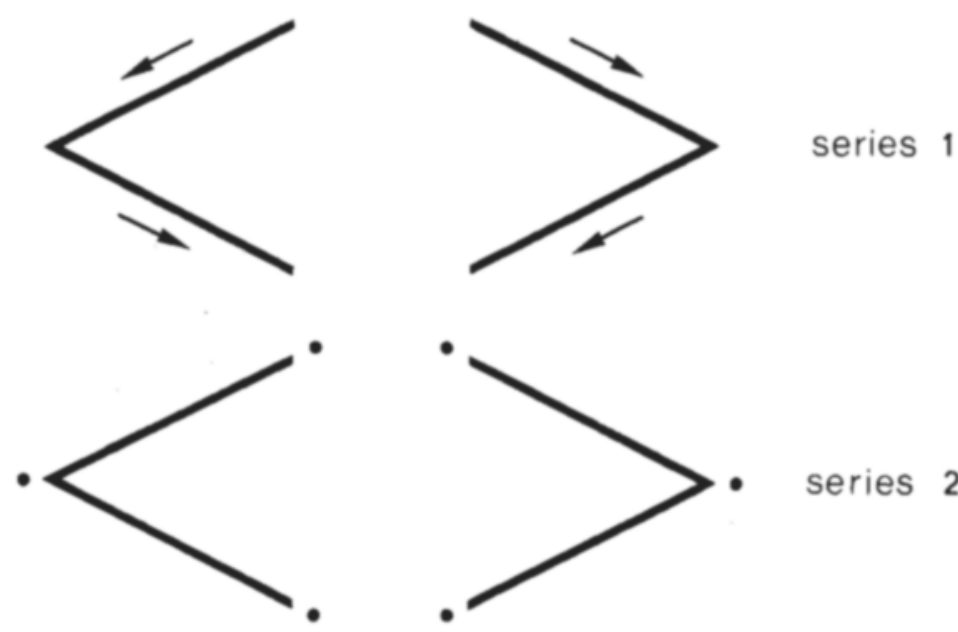

right hand

\section{series 2}

Fig. 1. Types of tactile exploration. The direction signs give the sense of the forefinger exploration. The points give the places where the fingers are put at the beginning of the multidigital exploration.

left form. A pretest was given to the child who had to answer after exploring both forms with one hand. During this pretest the child always performed well.

Each $T$ child successively used, during two alternating series, two types of exploration as follows (cf. Fig. 1):

(1) First type of exploration: With wrists and finger-joints being fixed on a splint in index-point position, the child was allowed to explore the two figures by shifting the tip of his forefingers on the velvet outlines with elbow- and shoulder-joint movements. This first type of exploration will be named "taut forefinger inspection."

(2) Second type of exploration: With elbow and shoulder joints being immobilized, the child was allowed to palpate the forms with all his fingers, restricting the activity only to wrist- and finger-joint movements. This second type of exploration will be named "multidigital palpation."

The $\mathrm{T}$ Ss were divided into two groups: Ta-children using the first type of exploration with the first series of items, then the second one with the second series of items; $\mathrm{Tb}$-children using the second type of exploration with the second series of items, then the first one with the first series.

In the $\mathrm{V}$ condition the $\mathrm{Ss}$ had to detect the forms using binocular vision only. They were divided into two groups ( $\mathrm{Va}$ and $\mathrm{Vb}$ ) with the two alternating series of items.

\section{RESULTS}

Table 1 gives the percentages of correct responses obtained in both conditions.

Sighted children gave statistically nonsignificantly $(\mathrm{p}>.10$, t test) different results for the two series of items, irrespective of the order of series presentation ( $\mathrm{Va}$ or $\mathrm{Vb}$ ). This nonsignificance allows us to regard the mean percentage $(86.6 \%)$ as the mean score obtained by sighted children.

Blindfolded children were always better when performing multidigital exploration (Series 2). With this multidigital exploration, the mean score ( $82.7 \%$ of well performed items) was statistically equivalent to the mean score $(86.6 \%)$ obtained by sighted children ( $p>.20$, t test). We can now compare the results obtained by blindfolded children for the two series (T1 and T2), seeing that the percentages are statistically equivalent either between $\mathrm{V} 1$ and $\mathrm{V} 2$, or between $\mathrm{V}$ and $\mathrm{T} 2$.

With the forefinger exploration (Series 1), the results showed an Table 1

Percentages of Correct Responses

\begin{tabular}{lcc}
\hline & \multicolumn{2}{c}{ Series } \\
\hline Groups & 1 & 2 \\
\hline $\mathrm{Va}$ & 81.6 & 88.3 \\
$\mathrm{Vb}$ & 90.0 & 86.6 \\
$\mathrm{Ta}$ & 73.3 & 85.3 \\
$\mathrm{~Tb}$ & 72.5 & 80.0 \\
\hline
\end{tabular}

impairment $(72.9 \%)$, as compared to the visual $(\mathrm{p}<.001$, t test) and multidigital $(\mathrm{p}<.05$, t test) situation.

\section{DISCUSSION}

In the tactile condition the seeing but blindfolded child could discriminate symmetrical forms as different with equal facility as in the visual situation only when he moved his fingers all together on the forms, that is, in the multidigital condition. What is well performed visually will also be well performed multidigitally (at 5 years, 6 months to 6 years of age). However, when he explored the forms with his forefingers, moving his elbows and shoulders, the child had difficulties in performing as he was asked to; i.e., he recognized more often two symmetrical forms as being identical.

Those results do not invalidate our starting hypothesis: The arm activity is more dependant on the principle of symmetry with regard to the median sagittal plane of the body, while the multidigital exploration does not seem to impair the transfer of the tactilely perceived form in the conventional (visual) context. The wrists and fingers can have an experience independant from the postural context, while the motor experience of the whole arm is bound to the reference of the arm in relation with the body in space.

Further explanations can be proposed. For example, the child can keep some reference marks during the multidigital exploration similar to the references in the visual situation, while the forefinger exploration only gives successive information by movement, and not on a figure as a whole.

However, different kinds of explanation can probably coexist. Their respective importance during the stages of child development has to be studied to explain the relations of the visual and kinesthetic space construction and representation.

\section{REFERENCES}

MELLO, N. K. Concerning the inter-hemispheric transfer of mirror-inage patterns in pigeon. Physiology \& Behavior, 1966, 1, 293-300.

NOBLE, J. Paradoxical interocular transfer of mirror-image discriminations in the optic chiasm sectioned monkey. Brain Research, $1968,10,127-151$.

OVER, R., \& OVER, J. Kinaesthetic judgements of the direction of line by young children. Quarterly Journal of Experimental Psychology, 1967, XIX, Part 4, 337-340.

PICK, H. L., JR., KLEIN, R. E., \& PICK, A. D. Visual and tactual identification of form orientation. Journal of Experimental Child Psychology, 1966, 4. 391-397.

ROBINSON, J. S.. \& HIGGINS, K. E. The young child's ability to see a difference between mirror image forms. Perceptual \& Motor Skills. 1967. 25, 893-897.

RLDEL, R. G.. \& TELBER, H. L. Discrimination of direction of line in children. Joumal of Comparative \& Physiological Psycholology, 1963. 56. 892-898. 